\title{
STUDIES ON THE PREVALENCE AND ETIOLOGY OF PELVIC INFLAMMATORY DISEASE AMONG WOMEN ATTENDING PRIMARY HEALTH CENTERS IN SOKOTO METROPOLIS
}

\author{
Kasarawa A.B. ${ }^{1}$, Mainasara S.S. ${ }^{2}$ and Salau I.A. ${ }^{3 *}$ \\ ${ }^{1}$ Department of Science Laboratory Technology, Umaru Ali Shinkafi Polytechnic, Sokoto \\ ${ }^{2}$ Sokoto State Primary Health Care Development Agency, Sokoto, Nigeria \\ ${ }^{* 3}$ Department of Biological Sciences, Federal University Gusau, Zamfara, Nigeria
}

*Corresponding Address Tel: +234(0) 8053569551 Email: ibrahimasalau@yahoo.com

Cite this article:

Kasarawa A.B., Mainasara S.S., Salau I.A. (2021),

Studies on the Prevalence and Etiology of Pelvic

Inflammatory Disease Among

Women Attending Primary

Health Centers in Sokoto

Metropolis. African Journal of

Health, Nursing and

Midwifery 4(4), 101-107.

DOI: 10.52589/AJHNM-

ZO5BMYSI.

\section{Manuscript History}

Received: 3 June 2021

Accepted: 9 July 2021

Published: 24 July 2021

Copyright $\odot 2020$ The Author(s). This is an Open Access article distributed under the terms of Creative Commons AttributionNonCommercial-NoDerivatives 4.0 International (CC BY-NC-ND 4.0), which permits anyone to share, use, reproduce and redistribute in any medium, provided the original author and source are credited.
ABSTRACT: Pelvic Inflammatory Disease (PID) is an inflammation of the uterus, fallopian tube, and ovaries as it progresses to scar leading to infertility and other reproductive problems. This research work was conducted to determine the etiology, antibiogram and prevalence of pelvic inflammatory disease among women attending Public Health Centres in Sokoto metropolis. The main objective of the study is to isolate the pathogens and determine the antibiotics sensitivity pattern and prevalence age of the Disease among the patients diagnosed with PID. 155 PID patients that were sorted by age and month were diagnosed within the year 2020. Laboratory assay on the etiology and antibiogram were carried out. From the total (155) patients diagnosed with PID in this study, thirty-three (33) were within the age of 15-20, forty-one (41) were between the ages of 21-25 and fifty-five (55) were between the age ranges of 26-30. The least (26) were between ages of 36 and 40. The highest prevalence age (35.5\%) in this study were observed to fall between the ages of 26-30 then followed by forty-one patients (26.5\%) prevalence that were between the ages of 21-25. The least in occurrence were 26 patients $(8.4 \%)$ that were between the age range of 36 and 40. Similarly, the results obtained from this study revealed that there were $77(49.67 \%)$ recorded in the first quarter of the year 2020. This was then followed by 48 (30.97\%) patients in the last quarter. The least occurrence of PID patients 30 (19.35\%) were diagnosed in the second quarter of the same year. The pathogens consistently identified to be associated with the disease were Neisseria gonorrhea and ciprofloxacin was the most sensitive on antibiogram. The factors responsible were poor personal hygiene, environmental pollution and unsanitary conditions of the toilets. It is recommended that patients should regularly visit health facilities for routine diagnosis of PID and ciprofloxacin and Broad spectrum antibiotics were the most efficacious for use in this study in the treatment of Pelvic inflammatory Disease.

KEYWORDS: PID, Prevalence, Etiology, Antibiogram, Public Health Centres 


\section{INTRODUCTION}

Pelvic Inflammatory Disease (PID) is an inflammation of the uterus, fallopian tubes and ovaries as it progresses to scar formation with adhesion to nearby tissues and has a wide range of clinical manifestation (Paavonen et al., 2008). The disease has many relationships with sexually transmitted infections (STDs) including Chlamydia trachomatis and Neisseria gonorrhea. Furthermore, Bendern et al. (2003) maintained that possible factors toward it development were identified to be lymphatic, postpartum post-abortion or Intra Uterine Contraceptive Device (IUCD). Also opined by Rekart et al. (2013) was that pelvic inflammatory is one of the infections in non-pregnant women of non-reproductive age.

In same vein, not all pelvic inflammatory disease are caused by sexually transmitted disease (STD), organism that are considered normal flora can be involved, and an individual case of inflammatory disease can be due to either a single organism or co-infection of the different species, $10 \%$ of women had asymptomatic Chlamydia trachomatis infection and $65 \%$ had asymptomatic infection with Neisseria gonorrhea.

The national Chlamydia screening program was progressively ruled out that Chlamydia trachomatis is the organism causing PID across England from 2003 to 2007. This left a window of opportunity from 2004-2008 to carry out community base trail, in a non-health care setting using self-taken samples in the Prevention of Pelvic Infection (POPI) trial investigated whether screening young sexually active female student for Chlamydial infection and treating those found to be infected, reduced the retrospective study of pelvic inflammatory disease in the subsequent 12 months. Also, exploratory study is carried out to investigate the retrospective study of pelvic inflammatory disease in women with untreated chlamydial infection (CDC, 2010).

The Center for Disease Control (2010) opined that clinical criterion increases the sensitivity of diagnostic criteria from $83 \%$ to $95 \%$. However, in 2002 the center (CDC) did not identify women with subclinical diseases. The US Center for Disease Control and Prevention (CDCP) estimates that more than one million women experience an episode of PID each year (CDC, 2011) as such young women are willing to give up 1-2 years of their life to prevent PID and its associated disorders.

The disease has clinically cryptic variation of symptoms but patients were sub-clinically asymptomatic. In a severe state of the disease (PID), patients experienced abdominal pain requiring surgical operation (Peipert and Ness, 2001). Trent et al. (2011) opined that Adolescent of age $<19$ years are more at risk of contracting PID than adult Women and factors responsible have been identified to be associated with multiple sex partners, engaging in unprotected sex as well as having high frequency of monogamous relationship

Research has however proved that the rates of PID diagnosed in black women were two-three times greater than those in white women in Hospital and ambulatory settings (Sutton et al., 2005). More recently, Goyal et al. (2013) established that race was associated with diagnosis of PID in adolescent patients. In consonance with these findings and considering the fact that this study was designed to be conducted in Nigeria among black women in Sokoto State who were more at high risk of contracting PID thus necessitate carrying out this study among patients attending specialist Hospital Sokoto. 
Furthermore, Nigerian citizens live below federal Poverty level and the rate of sexual violence against under aged children as well as young children engaged into prostitution in the study area has become alarming (SSHC, 2020). Thus, it exposes them to having multiple sex partners and the risk of contracting PID. A retrospective analysis of the NSFG from 2006 to 2010 showed that there are women with an income of $<150 \%$ of the Federal Poverty Level as measured by US census Cox et al. (2011)

Infertility and ectopic pregnancy are the leading cause of pregnancy related death in adult females. Additionally, CDC (2003) stated that infection can spread to peritoneum causing inflammation, leading to scar formation of the external surface of the liver. Multiple infections that are more likely to result in complications. Such complications and other consequential disorders have been observed among women diagnosed with PID in the Study area.

The study will help provide baseline information on the existence of the disease and its prevalence as it affects women at different age levels so that further research similar on the area can be conducted. The study will also recommend to authorities concern on the etiology and antibiotics for use in the treatment of PID diagnosed patients as well as recommend appropriate measures to take to curb the risk factors.

The study aimed to determine the Prevalence and etiology of Pelvic inflammatory Disease (PID) among women attending primary Health Centre in Sokoto metropolis.

\section{RESEARCH METHODOLOGY}

\section{Study Area}

Sokoto State, the semi-desert / Sahel State is geographically located in the extreme northwestern part of Nigeria. The State lies between longitudes $4^{\circ} 8^{\prime} \mathrm{E}$ and $6^{\circ} 54^{\prime} \mathrm{E}$ and latitudes $12^{\circ} \mathrm{N}$ and $13^{\circ} 58^{\prime} \mathrm{N}$. It shares borders with Zamfara State to the east, Kebbi State to the west and international boundary of Niger Republic to the north. The State has a tropical continental type (TCT) of climate dominated by two opposite air mashes: the tropical maritime from the south and tropical continental from the north. The tropical maritime climate brings moist conditions (Anon, 2000). Rainfall starts late in April and ends early in September and the mean annual rainfall ranges between $500 \mathrm{~mm}$ and $1300 \mathrm{~mm}$ (MOBEP, 2011), with peak in August. Dry-season starts from October and lasts up to April and the harmattan (dry, cold and dusty) wind is experienced in the State between November and February each year (RIM, 1992). Heat season is more severe in March and April and the average daytime temperature is put at $32^{\circ} \mathrm{C}$ with humidity less than $20 \%$ (MOBEP, 2011).

Sokoto State has a total land mass of 28, 232, 37 square kilometers and an estimated population of over three million six hundred thousand people (NPC, 2006). The State has twenty-three Local Government Areas divided into three Senatorial Zones namely Sokoto Central, Sokoto East and Sokoto South (NPC, 2009).

The study was carried out in Comprehensive Health Centre Kofar Rini, Sokoto North Local Government Area. The hospital is situated along Shehu Shagari Road in the Sokoto metropolis. It has a capacity of 80 beds in 8 wards that can accommodate both medical, surgical, pediatrics and gynecology cases. 


\section{Study Design}

A retrospective study was conducted to determine the prevalence, etiology and antibiogram of pelvic inflammatory disease among women attending primary Health Centre in Sokoto metropolis which involved the use of patient record from January to December 2020

\section{Target Population}

The target population of the study covers the entire patients that lodge complaints of STIs or showed apparent signs of pelvic inflammatory disease in primary Health Centre in Sokoto metropolis. During the period of the study, records of PID diagnosed patients from January to December 2020 were considered.

\section{Data Collection}

The technique used for data collection was the sorting out of the patient care folders obtained from the medical record department. The method is most appropriate since all the cases were recorded and accurately kept. The ages of PID diagnosed patients by month for the year 2020 was sorted out and recorded. Vaginal swabs were collected and analyzed during Laboratory diagnosis and isolates were subjected to an antibiogram.

\section{RESULTS}

Retrospective analysis of data collected from records of suspected PID patents revealed that all (155) PID patients were confirmed to have contracted sexually transmitted infection and has led to Pelvic Inflammatory Disease. All (100\%) patents were referred and subjected to laboratory investigation (Microbial Culture and Sensitivity test) that guided for appropriate treatment. However, from the total (155) patients diagnosed with PID in this study, thirty-three (33) were within the age of 15-20, forty-one (41) were between the ages of 21-25 and fifty five (55) were between the age ranges of 26-30. The least (26) were between ages of 36 and 40. The highest prevalence age (35.5\%) in this study was observed to fall between the ages of 2630 then followed by forty-one patients $(26.5 \%)$ prevalence that were between the ages of 2125 . The least in occurrence were 26 patients $(8.4 \%)$ that were between the age range of 36 and 40.

Table 1: The Distribution and prevalence by age of PID diagnosed patents

\begin{tabular}{lcc}
\hline Age Range & No. of PID patients & Prevalence (\%) \\
\hline $15-20$ & 33 & 21.29 \\
$21-25$ & 41 & 26.5 \\
$26-30$ & 55 & 35.5 \\
$31-35$ & $N i l$ & 0 \\
$36-40$ & 26 & 8.39 \\
\hline Total & 155 & $100 \%$ \\
\hline
\end{tabular}


Similarly, the results obtained from this study revealed that there were 77 (49.67\%) recorded in the first quarter of the year 2020. This was then followed by $48(30.97 \%)$ patients in the last quarter. The least occurrence of PID patients $30(19.35 \%)$ were diagnosed in the second quarter of the same year. Details is summarized in Table 2 below

Table 2: The Distribution and prevalence age of PID patients by quarter in 2020

\begin{tabular}{lcc}
\hline Quarter & No. of PID Patients diagnosed 2020 & Prevalence (\%) \\
\hline Jan-April & 77 & 49.09 \\
May-Aug & 30 & 18.18 \\
Sept-Dec & 48 & 32.73 \\
& & $100 \%$ \\
\hline Total & 155 &
\end{tabular}

Furthermore, the pathogens 'Neisseria gonorrhoea' were consistently recovered and have been identified to be associated with the disease and ciprofloxacin was the most efficacious antibiotic against the pathogens on sensitivity profiling.

\section{DISCUSSIONS}

Retrospective surveillance in this study has indicated a high degree of correlation between PID patients diagnosed by age and by quarter in 2020. The high prevalence of PID patients $(35.5 \%)$ which fall between the ages of 26-30 is in consonance with the report by WHO 2014 whose report indicates $33.4 \%$ and $37.0 \%$ respectively. The report emphasized that the high incidence of PID which was observed from women of between the age ranges of 26-30 was attributed to having sex without condom and for being sexually active stage of life.

Similarly, the least occurrence $(8.39 \%)$ was between the ages of 36-40. This finding was in agreement with the study of Klein and Wilson (2002) who reported $10.8 \%$ prevalence of women that have contracted PID. According to Klein and Wilson, the reason may be attributed to being restrained to only a single sex partner and multi-parity.

The infection in this study was observed to have high prevalence $(49.09 \%)$ in the first quarter (January - April) of the year 2020. This is in contrast with the report by Michod (2008) who opined that the high incidence may be attributed to seasonal ceremonies during which sexual orientation by youth becomes rampant.

Furthermore, Laboratory diagnosis of the PID patents in this study had revealed the etiology of the disease and was found to be microbial in nature and Neisseria gonorrheae have been consistently identified to be the bacterial pathogen associated with the disease from $95 \%$ of patents attending the primary health centre in Sokoto metropolis. The disease later radiates towards the upper reproductive tract and causes inflammation of the uterus and the oviducts with severe abdominal pain. This was in consonance with the findings of Paavonen et al. (2008) whose report showed that the disease on ultrasound scan (USS) revealed apparent inflammation 
of the ovaries, oviducts, uterus and the cervix. However, in the present study, the antibiotics determined to have high sensitivity against the pathogens were ciprofloxacin and Broad spectrum antibiotics. This is in line with the previous research as reported by Oakeshott et al. (2010) whose findings indicated similar regiments including cefoxitin, doxycycline and clindamycin plus gentamicin that were used in the treatment of PID patents

\section{CONCLUSION}

Pelvic inflammatory disease exists and is prevalent among women in the developed or developing communities. The infection is mostly contracted by women between the age range of 21-25 and 26-30 and is attributed to ignorance, indiscriminate application of herbal medicine in the treatment of PID, poor sanitation and toilet system as well as environmental pollution. There is the need for primary Health Educators to intensify efforts to enlighten the general public on the dangers of the disease (PID) in the community, especially those at higher risk of contracting the disease. Efforts should be geared toward discouraging the indiscriminate application of herbal medicine in the treatment of PID patents rather should be encouraged to visit health facilities for proper diagnosis and treatment by medical practitioners.

\section{REFERENCES}

Anon (2000): Guide to Sokoto state economic potentials. Ministry of Commerce Industry and Tourism, Sokoto Government Press Pp. 28

Bender N, Herrmann B and Andersen B. (2011): Chlamydia infection, pelvic inflammatory disease, ectopic pregnancy and infertility: cross-national study: Sexually Transmitted Infection, 87:601-608

CDC (2003) Gonorrhea Treatment". www.cdc.gov. 31 October 2017. Retrieved 7 December 2017.

CDC (2010): Centers for Disease Control and Prevention. Sexually transmitted disease surveillance

CDC (2011): Center for Disease Control and Prevention. Pelvic inflammatory disease (PID) CDC Fact Sheet

Cox S, Dean T and Posner SF. (2011): Disparities in reproductive health-related visits to the emergency department in Maryland by age and race, 1999-2005. Journal of Women's Health (Larchmt). 2011; 20(12):1833-1838.

Goyal M, Hersh A, Luan X, Localio R, Trent M and Zaoutis T. (2013): National trends in pelvic inflammatory disease among adolescents in the emergency department. Journal of Adolescence Health 2013; 53(2):249-252.

Klein JD and Wilson KM. (2002): Delivering quality care: Adolescents' discussion of health risks with their providers. Journal of Adolescent Health 30(3):190-195

Michod, Richard E.; Bernstein, Harris; Nedelcu, Aurora M. (2008). "Adaptive value of sex in microbial pathogens" (PDF). Infection, Genetics and Evolution. 8(3): 267-85. doi:10.1016/j.meegid.2008.01.002. PMID 18295550.

MOBEP (2011): Vision 20:20:20 First implementation plan (2010-2013), Sokoto State ministry of Budget and Economic Planning in vision MG GOL RC 717019.

NPC (2006): National Population Census Report Nigeria 
Oakeshott P, Kerry S, Aghaizu A. (2010): Randomised controlled trial of screening for Chlamydia trachomatis to prevent pelvic inflammatory disease: the POPI (Prevention of Pelvic Infection) trial 340: Pp.1642-1642

Paavonen J, Westrom L, Eschenbach D. (2008): Pelvic inflammatory disease. In:Holmes KK, Sparling PF, Stamm WE, et al., eds Sexually transmitted diseases. 4th ed. New York: McGraw-Hill, 2008.

Peipert JF, Ness RB and Blume J. (2001): Pelvic Inflammatory Disease Evaluation and Clinical Health Study Investigators.Clinical predictors of endometritis in women with symptoms and signs of pelvic inflammatory disease. American Journal Obstetrics and Gynaecolology 184(5): Pp. 856-863.

Rekart ML, Gilbert M and Meza R. (2013): Chlamydia public health programs and the epidemiology of pelvic inflammatory disease and ectopic pregnancy. Journal of Infectious Disease: 207:30-38

RIM (1992): Livestock Resources Four Volume Report to the Federal Government of Nigeria by Resource inventory and Management Ltd: in Report Executive Summary and Atlas; II-National Synthesis; III-State report; IV- Urban Report and Commercially Managed Livestock Survey Report. Pp.125

Sutton MY, Sternberg M, Zaidi A, St Louis ME, Markowitz LE. (2005): Trends in pelvic inflammatory disease hospital discharges and ambulatory visits, United States, 19852001. Sexually Transmitted Disease: 32(12): 778-784.

Trent M, Lehmann HP, Qian Q, Thompson CB, Ellen JM, Frick KD. (2011). Adolescent and parental utilities for the health states associated with pelvic inflammatory disease. Sexually Transmitted Infections: 87(7): 583-587. 